\title{
Response to Jeff McMahan
}

\author{
Michael Walzer
}

Published online: 4 August 2006

(C) Springer Science + Business Media B.V. 2006

I don't quite know how to respond to Jeff McMahan's critique of my terrorism essay since I don't think that I am making the kind of argument he thinks I am making. I do indeed offer a definition of terrorism, but my definition is meant to apply only to most cases; I don't mean to provide an account of what terrorism essentially is. I suppose that I should have written with more qualifiers, but my intentions, I think, are clear enough. And it is explicitly "from the perspective of the victims" that I describe terror as a "totalizing practice." So Jeff McMahan's twin assertions about "truth" leave me unmoved. I agree with both of them: It's not a factual truth that terrorists can't act for limited ends, and it's not a conceptual truth that when they do act for limited ends they are not terrorists. I only want to suggest what terrorism commonly signifies in the real world - most importantly, what it signifies to the men and women who are threatened by it. When I look at marginal cases, like the IRA, I try to show how my suggestion might work in those cases, not to offer a definitive account. I do believe that "most often they [the terrorists] have the totalizing intentions that their actions signal." But not always and not necessarily. The exceptional example doesn't bother me, since I am not looking for eternal or necessary truths.

The case is similar with my claim that terrorists make identity the basis of liability, "and that's a connection that we are morally bound to resist." I mean "identity" as it is understood in contemporary political discourse - as in "identity politics." I don't mean to rule out all possible connections in all hypothetical worlds or even in the real world. There are indeed names or titles that we might connect to an individual, and there are groups to which we might assign him, that are relevant to questions of liability. Doctors at the site of an accident are liable to different demands and judgments than the rest of us, but that is because of their profession, not because of their racial, national, or religious identity. The point of my argument is to distinguish different kinds of groups and to argue that membership in them has different social and moral implications. It's not a conceptual truth that group membership can never make individuals liable to attack. Liability depends on the character of the group. The primary distinction that I argue for is between the group of civilians and the group of soldiers or between societies/peoples/ nations/communities and armies. When I say that terrorists target people because of their membership, I mean their membership in a nation or a religious community. Do I sacrifice the

M. Walzer $(\bowtie)$

School of Social Science, Institute for Advanced Study, Einstein Drive, Princeton, NJ 08901-1411, USA

e-mail: walzer@ias.edu 
"theoretical integrity" of my argument when I also say that soldiers can legitimately be targeted because of their membership in an army? Only if theoretical integrity and common sense are radically at odds.

Jeff McMahan asks what I would think if a group of army members who have no connection to actual warfare - he mentions accountants, lawyers, and doctors; let's add cooks, laundrymen, nurses, and clerks - were assembled in an undefended building: Could we legitimately attack them? I don't know. If the army regularly brought together all its non-combat personnel without regard to their actual activities, then I would have to worry about Jeff McMahan's question. Since it doesn't, I don't. We commonly meet these people in close relation to the combat-ready soldiers whom they assist, and in that relationship, they are liable to attack. I should note, though, that medical personnel have almost always been taken to be immune - ever since the Middle Ages, I believe. They patch up soldiers and send them back into battle, but they also relieve human suffering, and under that second description they seem to belong to the larger human community and not to the army. I take them to be immune too, for that reason, at whatever cost to the theoretical integrity of my argument.

But if doctors in the army are immune from attack because of what they are doing, why can't we also mark out men and women in civilian society who are not immune because of their activities - if, for example, what they are doing makes them "morally responsible for the initiation or continuation of an unjust war." But even for Jeff McMahan, these civilians are not "usually" liable to military attack, and that is the only kind of liability I am writing about. I certainly agree that civilians can be liable to moral criticism and legal punishment. But the proposition that they can't "usually" be attacked sounds right to me, if what it means is that Jeff McMahan could come up with a hypothetical case in which we would all want to attack them. I won't start worrying about whether there is a significant difference between his "usually" and my "always" until the hypothetical cases start appearing in the real world.

Back to terrorism: Jeff McMahan thinks that terrorism is a crime of means, not of ends. But when terrorists aim, let's say, at the radical subordination of a group of people, surely they are guilty of a crime of ends. "But this is contingent," says Jeff McMahan, "it is not a necessary feature of terrorism." I accept that. It is only, as I have said, a common feature how common is an empirical question; we would have to look at (real) cases. I also want to argue, however, that this is the way people under threat experience terrorism and that this experience ought to weigh heavily in our moral and political judgments about the choice of terror.

Of course, I do think that there is a close, though certainly contingent, connection between terrorist means and ends. Jeff McMahan asks, "What if the US had not demanded unconditional surrender but had bombed Japanese cities in order to force a conditional surrender with guarantees of political and cultural independence for postwar Japan"? Would this have been terror bombing? My inclination is simply to return the question: Why is this a hypothetical, rather than an actual, case? Why are the political leaders who plan terrorist attacks so unlikely to think sympathetically about the "cultural independence" of the people they are attacking? What view of those people underlies the decision to attack them indiscriminately? I don't claim that there is a single necessary answer to these questions. But I do claim that the choice of terror is not simply a strategic choice; it is commonly connected to larger, and pernicious, moral views and political aims.

I have written a political essay (even though it is being published in a philosophical journal). My purpose is to argue against all the excuses and apologies that are made for 
terrorism and to urge a general condemnation - and then to insist that counter-terrorist activities meet the same moral standard that we apply, or should apply, to terrorists. Jeff McMahan doesn't attempt, and I assume would not want to make, an opposing political argument. He offers a philosophical critique, which would be entirely appropriate if I had written a philosophical essay. I don't mean to say that philosophical standards of consistency and clarity don't apply to political essays; they do. I meet them as best I can and sometimes, no doubt, fail to meet them. But arguments about necessary and contingent truths and strange hypothetical cases that no real-world actor will ever confront - these are not useful, it seems to me, in political debate. 